\title{
Cardiometabolic disorder reduces survival prospects more than suboptimal body mass index irrespective of age or gender: a longitudinal study of 377,929 adults in Taiwan
}

Chih-Cheng Hsu ${ }^{1,2,3}$, Mark L. Wahlqvist ${ }^{1,4^{*}}$, I-Chien Wu' ${ }^{1}$ Yu-Hung Chang ${ }^{5}$, I-Shou Chang ${ }^{1,6}$, Yi-Fen Tsai ${ }^{1}$, Ting-Ting Liư ${ }^{7}$, Chwen Keng Tsao ${ }^{7}$ and Chao A. Hsiung ${ }^{1 *}$

\begin{abstract}
Background: The effect of cardio-metabolic profile on the relationship of body mass index (BMI) with mortality is unclear. The aim of this study was to explore association between BMI and mortality at all ages, taking account of cardio-metabolic disorders.

Methods: We followed 377,929 individuals ( $\geq 20$ years), who registered for health checkups in 1996-2007, until 2008 and found 9490 deaths. From multivariable Cox proportional hazards models we estimated mortality hazard ratios (HR) for those in high blood pressure, hyperglycemia, high waist circumference, dyslipidemia, and different BMls categories (the underweight $\left[<18.5 \mathrm{~kg} / \mathrm{m}^{2}\right.$ ], low normal weight [18.5-21.9 kg/m²], normal weight [22-23.9 $\mathrm{kg} / \mathrm{m}^{2}$, the referent], overweight [24-26.9 kg/m²], obese1 [27-29.9 $\left.\mathrm{kg} / \mathrm{m}^{2}\right]$, and obese2 [ $\left.\geq 30 \mathrm{~kg} / \mathrm{m}^{2}\right]$ ). Population attributable risk (PAR) provided estimates of the population mortality burden attributable to high blood pressure, hyperglycemia, high waist circumference, dyslipidemia, and deviant BMls.

Results: Higher blood pressure, hyperglycemia, high waist circumference, and dyslipidemia were significantly predictive of higher mortality for nearly all ages. Compared with the referent BMI, underweight $(H R=1.69$, $95 \%$ confidence interval $=1.51-1.90)$ and low normal weight $(H R=1.19,1.11-1.28)$ were significant mortality risks, while overweight $(H R=0.82,0.76-0.89)$ and obese $1(H R=0.88,0.79-0.97)$ were protective against premature death. The mortality impact of obesity was largely attributable to cardio-metabolic profile and attenuated by age. The population mortality burden with high blood pressure (PAR $=7.29 \%)$, hyperglycemia (PAR $=5.15 \%)$, high waist circumference (PAR $=4.24 \%)$, and dyslipidemia ( $P A R=5.66 \%$ ) was similar to that in the underweight $(P A R=5.50 \%)$ or low normal weight $(P A R=6.04 \%)$ groups. Findings for non-smokers and by gender were similar.

Conclusions: The effect of BMI on mortality varies with age and is affected by cardio-metabolic status. Compared to any deviant BMI, abnormal cardio-metabolic status has a similar or even greater health impact at both the individual and population levels.
\end{abstract}

Keywords: Cardiometabolic disorder, Blood pressure, Glucose, Diabetes, BMI, Underweight, Obesity, Elderly, Mortality

\footnotetext{
* Correspondence: mark.wahlqvist@gmail.com; hsiung@nhri.org.tw

1 Institute of Population Health Sciences, National Health Research Institutes,

35 Keyan Road, Zhunan, Miaoli County, Taiwan

Full list of author information is available at the end of the article
}

(c) The Author(s). 2018 Open Access This article is distributed under the terms of the Creative Commons Attribution 4.0 International License (http://creativecommons.org/licenses/by/4.0/), which permits unrestricted use, distribution, and reproduction in any medium, provided you give appropriate credit to the original author(s) and the source, provide a link to the Creative Commons license, and indicate if changes were made. The Creative Commons Public Domain Dedication waiver (http://creativecommons.org/publicdomain/zero/1.0/) applies to the data made available in this article, unless otherwise stated. 


\section{Background}

There is a general understanding that the body mass index (BMI) in itself is a major determinant of mortality [1], although qualified by fat distribution for diseasespecific outcomes [2]. Historically, this may not always have been so [3]; but evidence from large-scale cohorts in both Western and Asian countries generally indicate that a BMI of $22-25 \mathrm{~kg} / \mathrm{m}^{2}$ may be optimal for prevention of premature death [1, 4-9]. While underweight $\left(\mathrm{BMI}<18.5 \mathrm{~kg} / \mathrm{m}^{2}\right)$ is usually recognized as a health hazard, especially for the elderly $[10,11]$, the mortality risk of a high BMI is probably attenuated by age $[4,5,12-16]$. However, to what extent the association between BMI and mortality is altered by cardiometabolic factors (CMFs) is unclear.

Apart from their apparent cardiovascular risks, metabolic syndrome (MetS) and insulin resistance could aggravate mortality risk in any BMI category [17]. The Emerging Risk Factors Collaboration [18] has demonstrated a reduced effect of obesity on the risk of coronary heart disease and ischemic stroke by adjustment for CMFs such as systolic blood pressure, history of diabetes, and lipid profiles. Presumptively, but not necessarily, the principal underlying disorder here is one of energy regulation manifest in a body compositional disorder, with CMFs acting in concert with or independently of BMI to determine mortality risk [19]. Few studies have been designed to evaluate the relative importance of CMFs. For example, in a meta-analysis [20], Flegal and colleagues concluded that obesity (BMI $\geq$ $30 \mathrm{~kg} / \mathrm{m}^{2}$ ) increases all-cause mortality while overweight $\left(\mathrm{BMI}=25-30 \mathrm{~kg} / \mathrm{m}^{2}\right)$ reduces it; however, age was not stratified, nor was cardio-metabolic risk taken into account. In an era when the prevalence of MetS has sharply increased [21], the predictive power of BMI for mortality relative to that of cardio-metabolic risk factors, particularly hypertension and hyperglycemia, is required.

For these reasons, we have studied a large population cohort of adult Taiwanese for up to 13 years to determine the mortality risk for BMI across a wide range and, at the same time, the mortality risks of CMFs so that we could establish their relative population attributable risk (PAR).

\section{Methods}

\section{Participants}

In this prospective cohort study, the participants came from the MJ Health Screening Center in Taiwan. The center's operations have been described elsewhere [22]. Briefly, 473,543 individual members were enrolled during 1996-2007 for health checkups at least once and followed to the end of 2008. Of these enrollees, 19,634 younger than 20 years (4.1\%); 20,491 with self-reported comorbidities of cancer, heart disease, or stroke at entry
(4.3\%); and 55,489 with incomplete anthropometric or laboratory data $(11.7 \%)$ were excluded. The remaining 377,929 participants were studied. The mean follow-up time for this selected cohort was 8.1 years.

\section{Measurements \\ Body mass index and its classification}

Anthropometric indicators comprised height and weight measurements. The BMI was calculated by dividing weight (in $\mathrm{kg}$ ) by the square of height (in meters). We primarily categorized BMI into four groups: underweight $\left(<18.5 \mathrm{~kg} / \mathrm{m}^{2}\right)$, normal weight $\left(18.5-23.9 \mathrm{~kg} / \mathrm{m}^{2}\right)$, overweight (24-26.9 kg/m $\left.{ }^{2}\right)$, and obese $\left(\geq 27 \mathrm{~kg} / \mathrm{m}^{2}\right)$, according to the definitions of the Department of Health in Taiwan [23]. Because the mortality risk might be lowest for people with a BMI of 22.5 to 25 [1, 4-9], we further subdivided the "normal" BMI category (which contained a majority of $55.9 \%$ of the participants) into "low normal" (18.5-21.9 kg/m²), and "normal" $\left(22-23.9 \mathrm{~kg} / \mathrm{m}^{2}\right.$ ) categories. Likewise, for the obesity group, the subsets of obese2 $\left(\geq 30 \mathrm{~kg} / \mathrm{m}^{2}\right)$ and obese1 $\left(27-29.9 \mathrm{~kg} / \mathrm{m}^{2}\right)$ were generated to acknowledge the WHO definition of obesity as a BMI $\geq 30 \mathrm{~kg} / \mathrm{m}^{2}[24]$.

\section{Metabolic syndrome (MetS)}

Overnight fasting blood was collected at entry and analyzed for plasma glucose, triglyceride, and HDL cholesterol using an auto-analyzer (Hitachi 7150, Tokyo, Japan). The modified NCEP/ATP III criteria were used for the diagnosis of the metabolic syndrome. A person who had three or more of the following risk components was considered to have MetS: waist circumference $\geq$ $90 \mathrm{~cm}$ in men or $\geq 80 \mathrm{~cm}$ in women, triglyceride $\geq 150 \mathrm{mg} / \mathrm{dL}$ or on anti-hyperlipidemia medication, HDL cholesterol $<40 \mathrm{mg} / \mathrm{dL}$ in men or $<50 \mathrm{mg} / \mathrm{dL}$ in women, blood pressure $\geq 130 / 85 \mathrm{mmHg}$ or on anti-hypertension medication, and fasting glucose $>100 \mathrm{mg} / \mathrm{dL}$ or on antidiabetes medication. In previous studies, the modified ATP III criteria have been shown to be predictive of mortality and cardiovascular diseases in Asians including Taiwanese [25].

\section{Death ascertainment}

The cohort database was linked to the electronic national death records between 1996 and 2008 by use of identification numbers (ID) but with a scrambling protocol to preserve anonymity. There were 9490 deaths identified during the follow-up period. Where date of death was not ascertainable in this way, we assumed participants were alive from the entry date until 31 December 2008. 


\section{Covariates}

In addition to BMI and metabolic parameters, other covariates for analysis included age, gender, education level, and the personal behaviors of smoking, alcohol drinking, and leisure time physical activity (LTPA). Baseline age was established from the enrollees' birth date and the date of the first health examination. We categorized participants into five age groups: 20-39, 40-49, 50-59, 60-69, and 70 years and over. Education was specified by school years and dichotomized as $\leq 6$ years and $>6$ years. Current smokers were those who smoked at least once a week; otherwise, subjects were defined as non-smokers. Current drinkers were those who drank an alcoholic beverage at least once a week. LTPA was dichotomized by frequency of engagement: "none or less than 1 hour per week" and "at least 1 hour per week."

\section{Statistical analysis}

Mean and standard deviation (SD) were used to describe continuous and percentages for categorical variables. Comparison of differences in means and percentages were performed using Student's t test and the chi-square test, respectively. For comparative mortality risk with BMI, we stratified participants into the 6 BMI groups by age as indicated. The mortality rate in the follow-up period was expressed as the number of deaths per 10,000 person years. The person-years were calculated as the time elapsed from the entry date until the date of death, or the end of follow-up, whichever came first. The calculation of a 95\% confidence interval (CI) for the mortality rate was based on the assumption that the number of deaths followed a Poisson distribution. We estimated the mortality rate in each BMI-age subgroup and with a further stratification by MetS status. We also calculated the mortality rate ratio (RR) to compare the mortality rate for individuals with MetS to those without MetS, in each BMI-age subgroup.

Multivariable Cox proportional hazards models were used to explore mortality risks of different BMIs, compared to the referent "normal" BMI $\left(22-23.9 \mathrm{~kg} / \mathrm{m}^{2}\right)$. Study entry was defined as the date of enrollment. Observations were censored at the end of the study or the date that individuals died, whichever occurred first. Results were expressed as hazard ratios (HRs) and 95\% CIs compared with the referent groups. To eliminate survival bias, we performed sensitivity analyses by exclusion of those who died within 1, 2, or 3 years after entry. Multivariable Cox regression analyses were also separately conducted for non-smokers, men, and women for the subgroup analysis. The proportional hazards assumption was evaluated by comparing estimated log-log survival curves for all covariates in each analysis. All assessed log-log survival plots graphically showed two parallel lines, indicating no violation of the assumption.
In addition, we assessed the proportion of disease burden in Taiwan attributable to different BMI, hypertension, and hyperglycemia for people at different age groups by calculating their population attributable risk (PAR) [26]. Analyses were performed with SAS software, version 9.1 (SAS Institute, Cary, NC). A two-sided $P$ value of 0.05 was considered statistically significant.

\section{Results}

The crude mortality rate of study subjects in different age-BMI matches is shown in Table 1 . For those younger than 50, overweight and obesity are associated with higher death rates; however, for people older than 50, those in the overweight category have the lowest mortality rate and those who are underweight have the highest. People with MetS generally have moderately higher mortality rates (mortality rate ratio $(R R)=1.2-2.8$ ), irrespective of age-BMI category - except for those in the group with $\mathrm{BMI} \geq 30 \mathrm{~kg} / \mathrm{m}^{2}$ (RR inconsistent) or in the underweight younger groups ( $<50$ years, $R R=5.5-11.6)$, who have much higher mortality rates.

The multivariable adjusted hazard ratios (HR) are shown in Fig. 1 (for subjects overall) and 2 (for those with MetS). Using those with $\mathrm{BMI}=22-23.9 \mathrm{~kg} / \mathrm{m}^{2}$ as referent, the obese and underweight were more likely to die; the mortality risk of obesity is even more apparent in the younger groups (Fig. 1a). Figure 1b shows an increasing proportion with both high blood pressure and hyperglycemia with increasing BMI at all ages. However, for those with MetS, the mortality risk of being underweight is much greater than that of obesity, especially for younger people (Fig. 2a). Figure $2 \mathrm{~b}$ reveals a high proportion with both high blood pressure and hyperglycemia in each age-BMI category, particularly and homogeneously in the underweight groups (65-85\%), but with more of a gradient by age in the higher BMI categories. This indicates that the high mortality in underweight groups who have MetS is predominantly related to CMFs.

Figure 3 shows the subgroup analyses, indicating a similar mortality pattern among the different age-BMI groups for subjects overall, as for the subgroups of non-smokers, whether men or women. The mortality risks of high blood pressure and hyperglycemia were both significant for those older than 50 in subjects overall, as well as in each subgroup. In order to eliminate indication bias, we conducted sensitivity analyses by deleting those who died within 1, 2, or 3 years, and we obtained similar findings (shown in Additional file 1: Table S1). The results were also robust in the models additionally adjusted for waist circumference (Additional file 1: Figure S1). In another subgroup analysis, we added those who had self-reported heart disease or stroke into our study subjects $(N=390,941)$ to assess the robustness of 


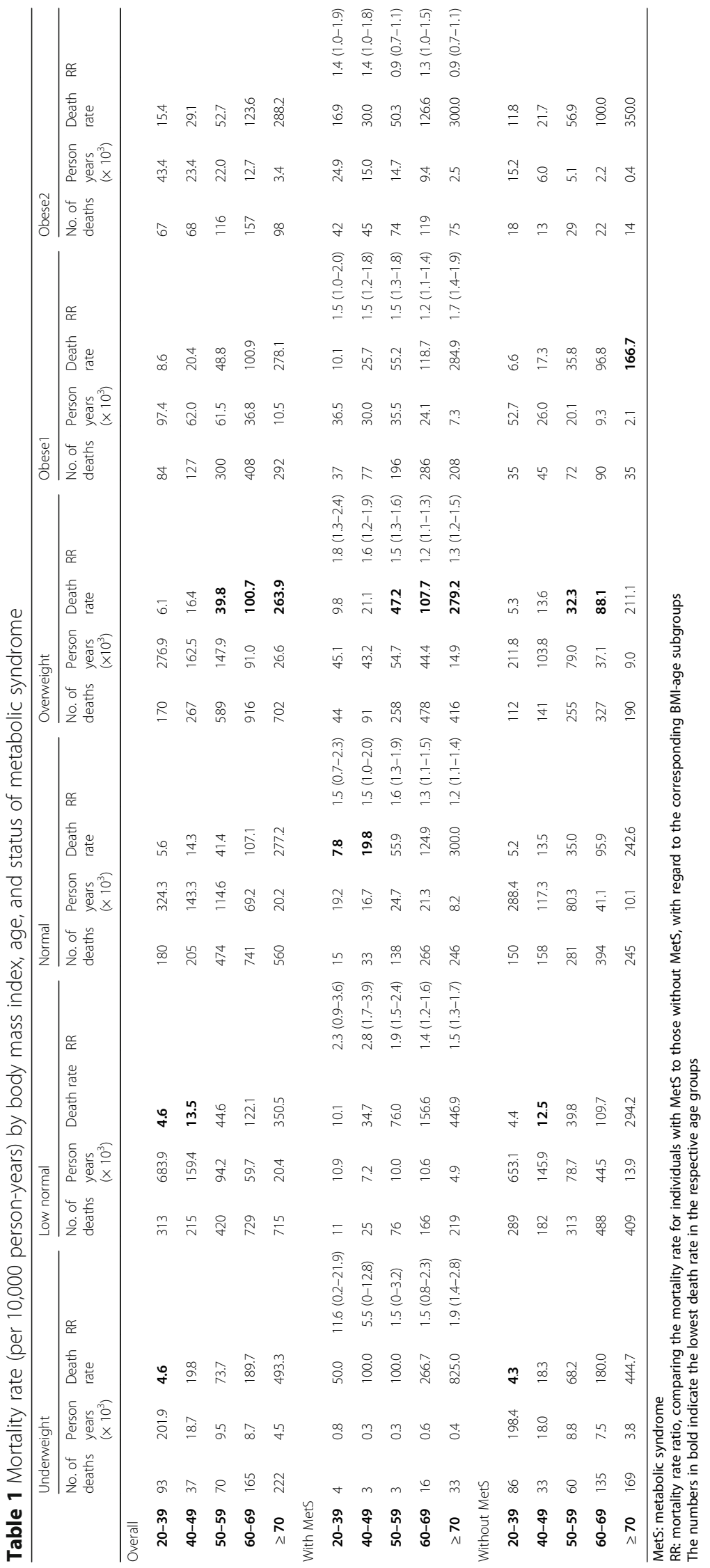




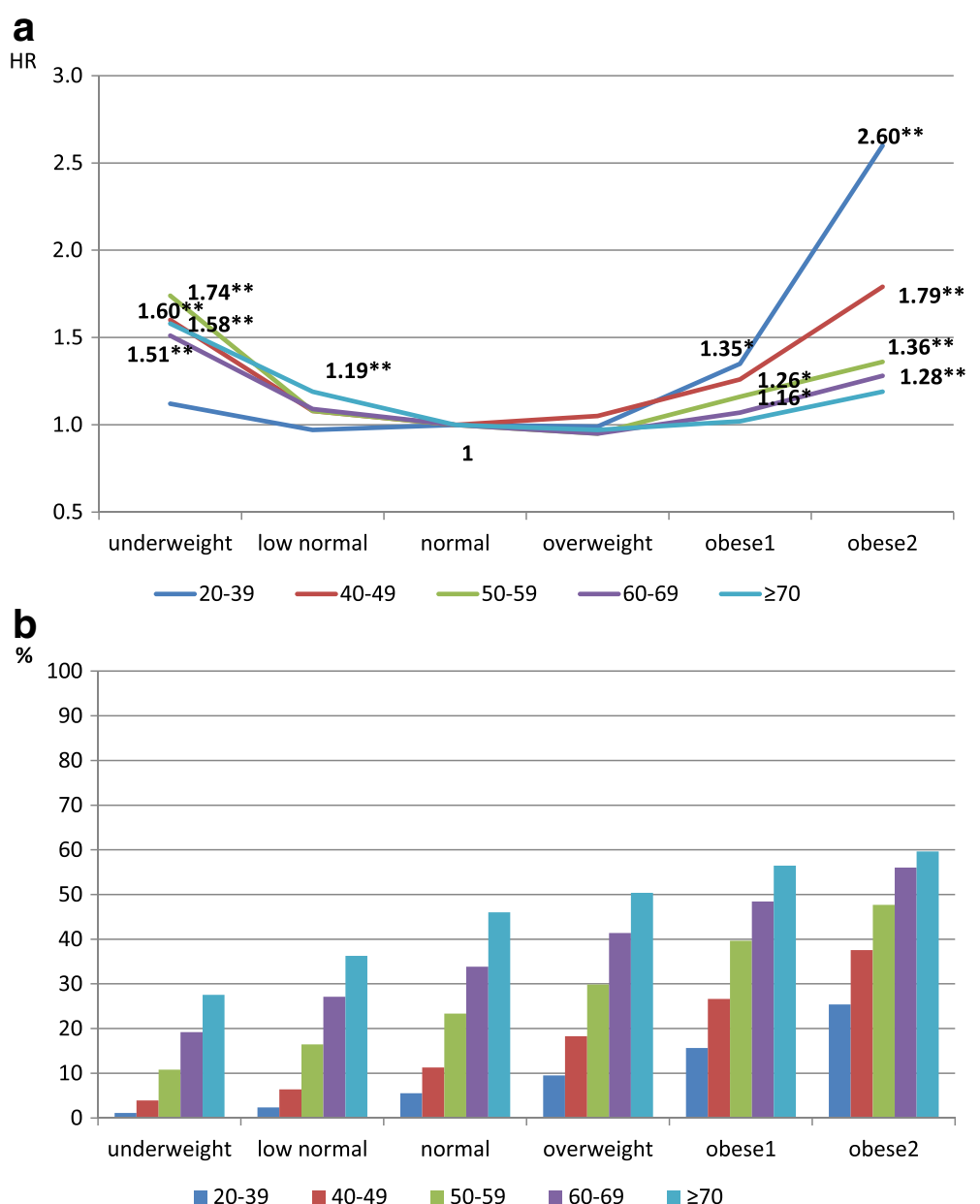

Fig. 1 All-cause mortality risk (1a) and proportion of high blood pressure and hyperglycemia (1b) in different BMI categories for overall study subjects stratified by age. The hazards ratios shown in 1A were derived from Cox proportional hazards models adjusted for gender, age, education level, smoking status, physical activity, and drinking status. ${ }^{*} P<0.05,{ }^{*} P<0.01$

the relationship between metabolic risk factors and mortality. As shown in Additional file 1: Table S2, the results were similar.

The comparison of the PAR for mortality between different BMI, high blood pressure, hyperglycemia, central obesity (higher waist circumference), and dyslipidemia is shown in Table 2. For subjects overall, the PARs for underweight, low normal weight, and obese 2 were $5.5 \%, 6.0 \%$, and $0.4 \%$, respectively, all of which were lower than the PARs for high blood pressure $(7.3 \%)$. Except for those $\geq 70$ (with high PARs for underweight and low normal weight: $5.1 \%$ and $7.2 \%$, respectively), the population mortality burdens of high blood pressure, hyperglycemia, central obesity, and dyslipidemia were generally higher than that caused by deviant BMI categories, related to the high prevalence of cardio-metabolic disorders in all age groups.

\section{Discussion}

The current study demonstrates the mortality risks of different body mass indices for adults at all ages in regard to individual cardio-metabolic profiles. A U-shaped relationship between all-cause mortality and BMI for subjects overall changes to an L-shaped association when the analysis is restricted to those having metabolic syndrome. For those with MetS, obesity-related excess mortality largely disappears except among the youngest ( $<40$ years). At the same time, blood pressure and blood glucose have a high PAR for mortality in both younger and older individuals, and are relevant for the prevention of premature death, irrespective of gender or body composition. The PARs for high blood pressure and hyperglycemia are $8.57 \%$ and $6.49 \%$, respectively - higher than those for underweight $(\mathrm{PAR}=5.80 \%)$, low normal weight $\quad(\mathrm{BMI}=18.5-22, \quad \mathrm{PAR}=5.43 \%), \quad$ and obesity $(\mathrm{BMI}>30, \mathrm{PAR}=1.04 \%)$. The sample sizes in the present 


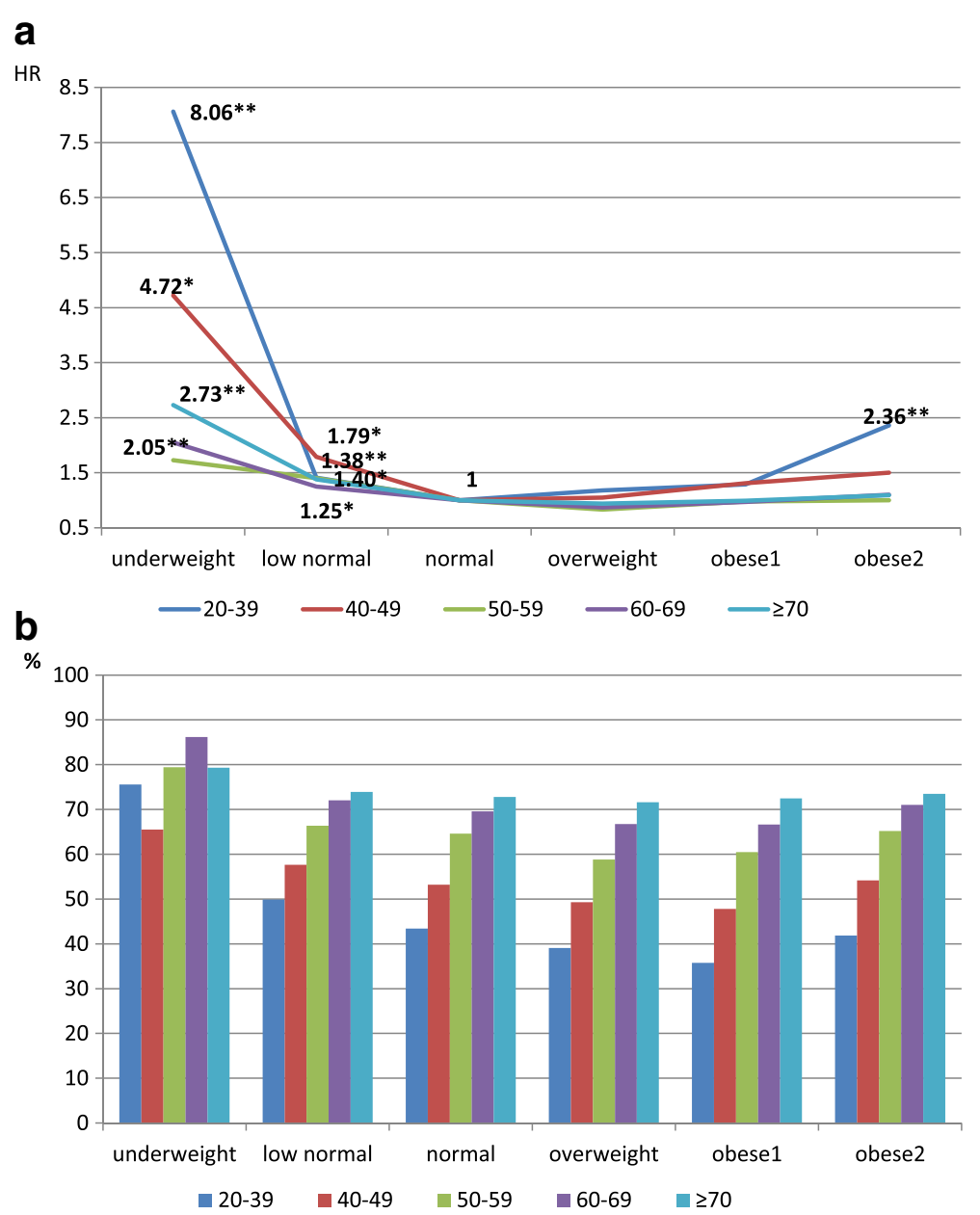

Fig. 2 All-cause mortality risk (2a) and proportion of subjects with both high blood pressure and hyperglycemia (2b) in different BMI categories for subjects with the metabolic syndrome, stratified by age. The hazard ratios shown in 2A were derived from Cox proportional hazards models adjusted for gender, age, education level, smoking status, physical activity, and drinking status. ${ }^{*} P<0.05,{ }^{* *} P<0.01$

study are large enough to conduct subgroup analyses and explore the complex relationships between cardiometabolic disorders, BMI, and mortality. We are also able to consider the role played by traditional cardiovascular risk factors on the health effects of BMI across the entire adult life course, which is missing in most studies of BMI and mortality.

\section{Underweight}

Underweight is a well-recognized health risk for elders $[1,5,6,10,11]$, in whom it may reflect a range of nutritional inadequacies, chronic energy deficiency, or sarcopenia [27]. However, the mortality risk of underweight for younger people is controversial; some studies reported that the U-shaped relationship between BMI and mortality also applies to younger adults $[5,7,16]$, while others have found the risk to be lowest among younger subjects with the lowest BMI $[28,29]$. In the current study, when the entire dataset was analyzed, we found that being underweight increased mortality risk by $51-$ $74 \%(\mathrm{HR}=1.51-1.74)$ for those older than 40 years, but also that it was not a significant risk factor in multivariable models for those younger than 40 years. However, in the presence of MetS, being underweight was hazardous for premature mortality at almost all ages; this was particularly so for the youngest subgroup (20-39 years) with MetS, who experienced the highest mortality risk from being underweight $(\mathrm{HR}=8.06, p<0.01)$ (Fig. 2a). One of reasons that being underweight shifts from insignificance to high risk in the youngest group may be that the proportion with both high blood pressure and hyperglycemia escalates from only $1.1 \%$ in subjects overall to $75.6 \%$ for the underweight with MetS. The differences in the proportion with both high blood pressure and blood glucose in other age groups is also key to the link between being underweight and all-cause mortality; for 


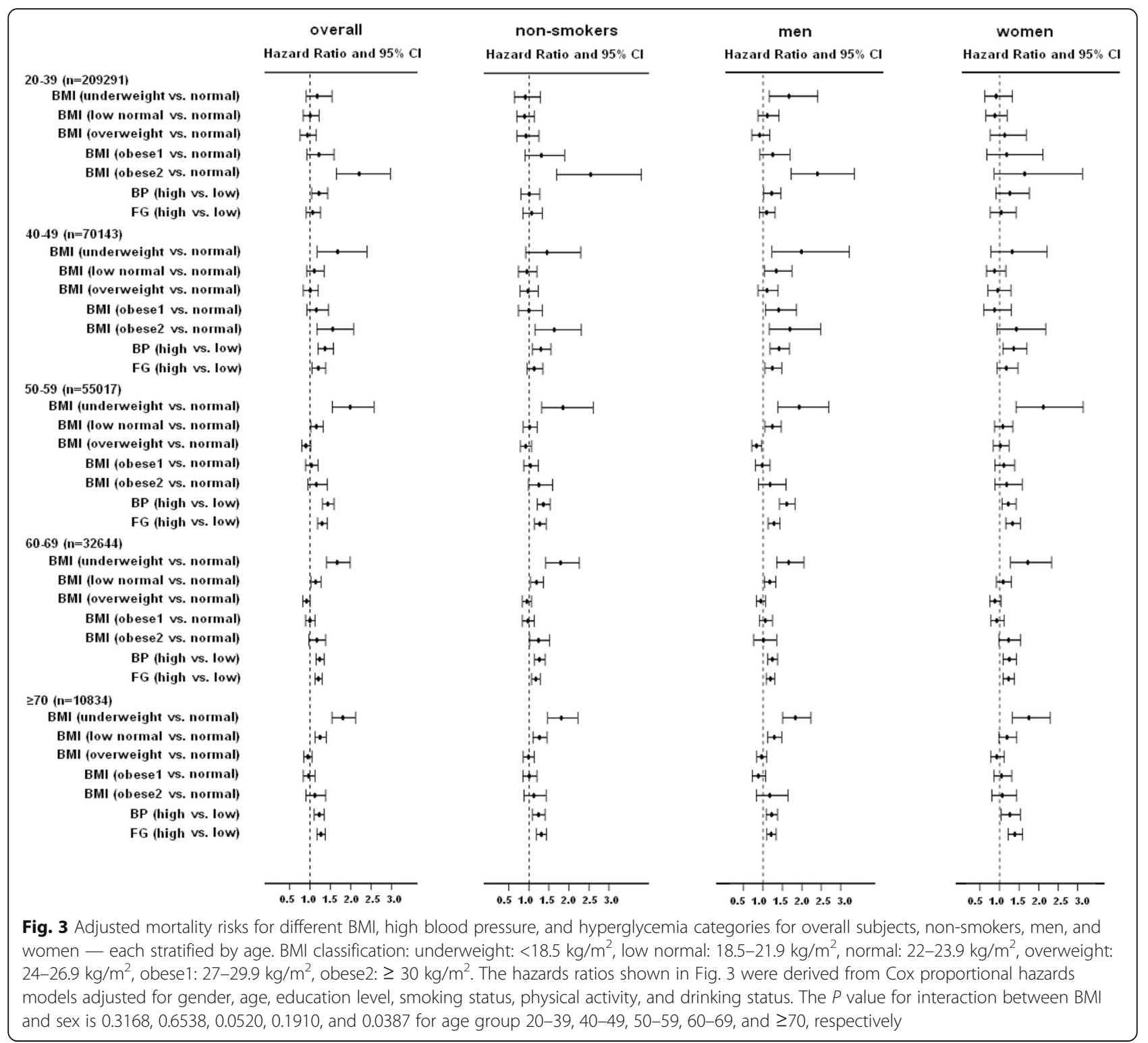

example, for those aged 40-49 years, when the proportion increased from $3.9 \%$ for subjects overall to $65.5 \%$ for those with MetS, the mortality risk rose 2.8 -fold $(\mathrm{HR}=1.66$ to 4.72$)$.

\section{Metabolic syndrome and BMI}

We found that the relative mortality risk with and without MetS varies between different age and BMI groups. In general, MetS increases the mortality rate less than 2fold; its influence is intensified in the young underweight category ( $R R=11.6$ for the youngest age group with vs. without MetS), but is gradually attenuated with age. Our findings are in accord with most previous studies, which indicate that the mortality risk of MetS is principally identifiable in younger or middle-aged people [17-30], but not in the elderly [31, 32], except where there is other morbidity, such as chewing difficulty [33].

\section{Age}

The current study also reveals that age-associated links between BMI and mortality are largely attributable to and more evident by way of 2 components of MetS: high blood pressure and hyperglycemia. We found the mortality risk for hypertension to be $\mathrm{HR}=1.22$ and 1.23 for those in the 20-39 years and $>70$ years groups, respectively; and for hyperglycemia, $\mathrm{HR}=1.07$ and 1.27 , respectively, with the risks not attenuated by age. Rather, the prevalence of these risk factors substantially increases from $<20 \%$ in the youngest group to about $60-$ $70 \%$ in the oldest group. As a result, the PARs of high 
Table 2 Mortality risk, prevalence, and population attributable burden of mortality for different BMl, high blood pressure, and hyperglycemia in overall subjects and people in different age groups

\begin{tabular}{|c|c|c|c|c|c|c|}
\hline & Model $1 \mathrm{HR}$ & Model $2 \mathrm{HR}$ & Model $3 \mathrm{HR}$ & $95 \% \mathrm{Cl}$ & Prevalence (\%) & PAR (\%) \\
\hline \multicolumn{7}{|l|}{ Overall $(n=377,929$, death $=9490)$} \\
\hline Underweight (vs. normal BMI) & $0.77^{* * *}$ & $1.54^{* * *}$ & $1.69 * * *$ & $(1.51-1.90)$ & 8.43 & 5.50 \\
\hline Low normal (vs. normal BMI) & $0.74^{* * *}$ & $1.11 * * *$ & $1.19 * * *$ & $(1.11-1.28)$ & 33.80 & 6.04 \\
\hline Normal BMI & 1 & 1 & 1 & - & 22.10 & - \\
\hline Overweight (vs. normal BMI) & $1.17^{* * *}$ & 0.97 & $0.82^{* * *}$ & $(0.76-0.89)$ & 23.17 & -4.35 \\
\hline Obese1 (vs. normal BMI) & $1.39 * * *$ & $1.12^{* *}$ & $0.88^{* *}$ & $(0.79-0.97)$ & 8.89 & -1.08 \\
\hline Obese2 (vs. normal BMI) & $1.52^{* * *}$ & $1.45^{* * *}$ & 1.12 & $(0.98-1.28)$ & 3.61 & 0.43 \\
\hline High BP (vs. normal BP) & $3.86^{* * *}$ & $1.32^{* * *}$ & $1.26^{* * *}$ & $(1.19-1.34)$ & 30.22 & 7.29 \\
\hline High FG (vs. normal FG) & $2.57^{* * *}$ & $1.25^{* * *}$ & $1.18^{* * *}$ & $(1.12-1.24)$ & 30.17 & 5.15 \\
\hline High WC (vs. normal WC) & $2.50 * * *$ & $1.13^{* * *}$ & $1.24 * * *$ & $(1.15-1.33)$ & 18.47 & 4.24 \\
\hline Dyslipidemia vs. normal TG/HDL & $1.36^{* * *}$ & $1.12^{* * *}$ & $1.14 * * *$ & $(1.08-1.20)$ & 42.89 & 5.66 \\
\hline \multicolumn{7}{|l|}{ 20-39 $(n=209,291$, death $=907)$} \\
\hline Underweight (vs. normal BMI) & 0.85 & 1.12 & 0.94 & $(0.68-1.30)$ & 12.67 & -0.77 \\
\hline Low normal (vs. normal BMI) & $0.82 *$ & 0.97 & 1.00 & $(0.80-1.25)$ & 41.22 & 0.00 \\
\hline Normal BMI & 1 & 1 & 1 & - & 19.80 & - \\
\hline Overweight (vs. normal BMI) & 1.11 & 0.99 & 0.85 & $(0.65-1.10)$ & 17.19 & -2.65 \\
\hline Obese1 (vs. normal BMI) & $1.57^{* * *}$ & $1.35^{*}$ & 1.00 & $(0.69-1.47)$ & 6.21 & 0.00 \\
\hline Obese2 (vs. normal BMI) & $2.87^{* * *}$ & $2.60 * * *$ & $1.65^{*}$ & $(1.04-2.60)$ & 2.92 & 1.86 \\
\hline High BP (vs. normal BP) & $1.57^{* * *}$ & $1.37^{* * *}$ & 1.17 & $(0.97-1.43)$ & 16.85 & 2.78 \\
\hline High FG (vs. normal FG) & $1.42^{* * *}$ & $1.18^{*}$ & 1.10 & $(0.91-1.34)$ & 19.15 & 1.88 \\
\hline High WC (vs. normal WC) & $2.10^{* * *}$ & $1.70^{* * *}$ & 1.33 & $(0.97-1.82)$ & 10.20 & 3.26 \\
\hline Dyslipidemia vs. normal TG/HDL & $1.38^{* * *}$ & $1.23^{* *}$ & $1.19^{*}$ & $(1.01-1.41)$ & 37.91 & 6.72 \\
\hline \multicolumn{7}{|l|}{$40-49(n=70,143$, death $=919)$} \\
\hline Underweight (vs. normal BMI) & $1.44^{*}$ & $1.60^{* *}$ & $1.66^{*}$ & $(1.10-2.50)$ & 3.57 & 2.30 \\
\hline Low normal (vs. normal BMI) & 0.96 & 1.08 & 1.15 & $(0.91-1.44)$ & 28.60 & 4.11 \\
\hline Normal BMI & 1 & 1 & 1 & - & 24.81 & - \\
\hline Overweight (vs. normal BMI) & 1.15 & 1.05 & 0.92 & $(0.73-1.17)$ & 28.16 & -2.30 \\
\hline Obese1 (vs. normal BMI) & $1.43^{* *}$ & $1.26^{*}$ & 1.11 & $(0.80-1.53)$ & 10.80 & 1.17 \\
\hline Obese2 (vs. normal BMI) & $2.03^{* * *}$ & $1.79^{* * *}$ & 1.43 & $(0.95-2.16)$ & 4.07 & 1.72 \\
\hline High BP (vs. normal BP) & $1.61^{* * *}$ & $1.43^{* * *}$ & $1.28^{* *}$ & $(1.08-1.51)$ & 30.47 & 7.86 \\
\hline High FG (vs. normal FG) & $1.44^{* * *}$ & $1.27^{* * *}$ & 1.12 & $(0.95-1.33)$ & 35.44 & 4.08 \\
\hline High WC (vs. normal WC) & $1.43^{* * *}$ & $1.22 *$ & 1.11 & $(0.86-1.42)$ & 20.45 & 2.20 \\
\hline Dyslipidemia vs. normal TG/HDL & $1.17^{*}$ & 1.04 & 1.00 & $(0.84-1.18)$ & 46.82 & 0.00 \\
\hline \multicolumn{7}{|l|}{$50-59(n=55,017$, death $=1969)$} \\
\hline Underweight (vs. normal BMI) & $1.83^{* * *}$ & $1.74^{* * *}$ & $1.77^{* * *}$ & $(1.28-2.43)$ & 2.21 & 1.67 \\
\hline Low normal (vs. normal BMI) & 1.09 & 1.08 & $1.19^{*}$ & $(1.01-1.40)$ & 21.36 & 3.90 \\
\hline Normal BMI & 1 & 1 & 1 & - & 25.45 & - \\
\hline Overweight (vs. normal BMI) & 0.96 & 0.95 & $0.74^{* * *}$ & $(0.63-0.87)$ & 32.58 & -9.26 \\
\hline Obese1 (vs. normal BMI) & $1.17^{*}$ & $1.16^{*}$ & $0.76^{*}$ & $(0.62-0.95)$ & 13.48 & -3.34 \\
\hline Obese2 (vs. normal BMI) & $1.28^{*}$ & $1.36^{* *}$ & 0.88 & $(0.66-1.17)$ & 4.92 & -0.59 \\
\hline High BP (vs. normal BP) & $1.46^{* * *}$ & $1.46^{* * *}$ & $1.48^{* * *}$ & $(1.32-1.67)$ & 50.32 & 19.45 \\
\hline High FG (vs. normal FG) & $1.39 * * *$ & $1.35^{* * *}$ & $1.17^{* *}$ & $(1.05-1.31)$ & 46.95 & 7.39 \\
\hline High WC (vs. normal WC) & $1.23 * * *$ & $1.23^{* * *}$ & $1.39 * * *$ & $(1.19-1.62)$ & 31.63 & 10.98 \\
\hline Dyslipidemia vs. normal TG/HDL & $1.14^{* *}$ & 1.09 & 1.09 & $(0.97-1.23)$ & 49.40 & 4.26 \\
\hline
\end{tabular}


Table 2 Mortality risk, prevalence, and population attributable burden of mortality for different BMI, high blood pressure, and hyperglycemia in overall subjects and people in different age groups (Continued)

\begin{tabular}{|c|c|c|c|c|c|c|}
\hline & Model $1 \mathrm{HR}$ & Model $2 \mathrm{HR}$ & Model 3 HR & $95 \% \mathrm{Cl}$ & Prevalence (\%) & PAR (\%) \\
\hline \multicolumn{7}{|l|}{$60-69(n=32,644$, death $=3116)$} \\
\hline Underweight (vs. normal BMI) & $1.77^{* * *}$ & $1.51 * * *$ & $1.74^{* * *}$ & $(1.41-2.14)$ & 3.14 & 2.27 \\
\hline Low normal (vs. normal BMI) & $1.14^{*}$ & 1.09 & 1.14 & $(1.00-1.29)$ & 21.59 & 2.93 \\
\hline Normal BMI & 1 & 1 & 1 & - & 24.97 & - \\
\hline Overweight (vs. normal BMI) & 0.94 & 0.95 & $0.82^{* *}$ & $(0.72-0.93)$ & 32.45 & -6.20 \\
\hline Obese1 (vs. normal BMI) & 1.03 & 1.07 & 0.85 & $(0.72-1.02)$ & 13.15 & -2.01 \\
\hline Obese2 (vs. normal BMI) & 1.16 & $1.28 * *$ & 1.00 & $(0.79-1.26)$ & 4.69 & 0.00 \\
\hline High BP (vs. normal BP) & $1.19 * * *$ & $1.24^{* * *}$ & $1.22^{* * *}$ & $(1.10-1.34)$ & 65.80 & 12.65 \\
\hline High FG (vs. normal FG) & $1.19^{* * * *}$ & $1.22^{* * *}$ & $1.16^{* *}$ & $(1.06-1.27)$ & 52.60 & 7.76 \\
\hline High WC (vs. normal WC) & 0.95 & 1.05 & $1.17^{*}$ & $(1.04-1.33)$ & 39.28 & 6.26 \\
\hline Dyslipidemia vs. normal TG/HDL & $1.12^{* *}$ & $1.15^{* * *}$ & $1.14^{* *}$ & $(1.04-1.25)$ & 52.32 & 6.82 \\
\hline \multicolumn{7}{|l|}{$\geq 70(n=10,834$, death $=2579)$} \\
\hline Underweight (vs. normal BMI) & $1.80^{* * *}$ & $1.58^{* * *}$ & $1.96^{* * *}$ & $(1.61-2.39)$ & 5.63 & 5.13 \\
\hline Low normal (vs. normal BMI) & $1.27^{* * *}$ & $1.19^{* *}$ & $1.32^{* * *}$ & $(1.15-1.52)$ & 24.19 & 7.19 \\
\hline Normal BMI & 1 & 1 & 1 & - & 23.47 & - \\
\hline Overweight (vs. normal BMI) & 0.95 & 0.97 & 0.87 & $(0.75-1.01)$ & 30.64 & -4.15 \\
\hline Obese1 (vs. normal BMI) & 0.96 & 1.02 & 0.90 & $(0.74-1.10)$ & 12.13 & -1.23 \\
\hline Obese2 (vs. normal BMI) & 1.05 & 1.19 & 1.18 & $(0.90-1.54)$ & 3.93 & 0.70 \\
\hline High BP (vs. normal BP) & $1.16^{* *}$ & $1.20^{* * *}$ & $1.13^{*}$ & $(1.01-1.28)$ & 77.69 & 9.17 \\
\hline High FG (vs. normal FG) & $1.22^{* * *}$ & $1.25^{* * *}$ & $1.26^{* * *}$ & $(1.14-1.39)$ & 56.11 & 12.73 \\
\hline High WC (vs. normal WC) & 0.91 & 1.02 & $1.21 * *$ & $(1.06-1.39)$ & 45.31 & 8.69 \\
\hline Dyslipidemia vs. normal TG/HDL & 1.05 & $1.09 *$ & $1.19 * * *$ & $(1.07-1.32)$ & 51.98 & 8.99 \\
\hline
\end{tabular}

${ }^{*} P<0.05,{ }^{* * P}<0.01,{ }^{* * *} P<0.001$

BMI: body mass index, BP: blood pressure, FG: fasting glucose level, WC: waist circumference, TG: triglyceride, HDL: high density lipoprotein cholesterol BMI classification: Underweight: $<18.5 \mathrm{~kg} / \mathrm{m}^{2}$, low normal: $18.5-21.9 \mathrm{~kg} / \mathrm{m}^{2}$, normal: $22-23.9 \mathrm{~kg} / \mathrm{m}^{2}$, overweight: $24-26.9 \mathrm{~kg} / \mathrm{m}^{2}$, obese1: $27-29.9 \mathrm{~kg} / \mathrm{m}^{2}$, obese2: $\geq 30 \mathrm{~kg} / \mathrm{m}^{2}$

High BP: blood pressure $\geq 130 / 85 \mathrm{mmHg}$ or on anti-hypertension medication

High FG: fasting glucose $>100 \mathrm{mg} / \mathrm{dL}$ or on anti-diabetes medication

High waist circumference: $\geq 90 \mathrm{~cm}$ in men or $\geq 80 \mathrm{~cm}$ in women

Dyslipidemia: abnormal TG ( $\geq 150 \mathrm{mg} / \mathrm{dL}$ or on anti-hyperlipidemia medication) or abnormal $\mathrm{HDL}$ ( $<40 \mathrm{mg} / \mathrm{dL}$ in $\mathrm{men}$ or $<50 \mathrm{mg} / \mathrm{dL}$ in women)

Model 1: univariate Cox proportional hazards models

Model 2: adjusted for sex, age, education level, smoking status, physical activity, and drinking status

Model 3: adjusted for sex, age, education level, smoking status, physical activity, drinking status, BP, FG, WC and dyslipidemia

$95 \%$ confidence interval for hazards ration in Model 3

blood pressure and hyperglycemia increase with age, higher than the mortality burden presented by any deviant BMI at any age. These findings are consistent with prior studies. Thomas et al. followed a French cohort for 5 years and showed that hypertension, rather than other components of MetS, remained a significant predictor of all-cause mortality $(H R=1.3)$ in the multivariable models for those $>65$ [32]. Mozaffarian and colleagues followed an American elderly cohort in the Cardiovascular Health Study for 15 years [34] and found that the association of MetS with mortality was largely confined to those who had hypertension or abnormal glucose metabolism; for those with MetS but an absence of hypertension or hyperglycemia, the mortality risk was not significantly higher than for those without MetS.

\section{Strengths and limitations}

The present study is notable for its large sample size and longitudinal study design. By the exclusion of individuals with severe comorbidities such as cancer, stroke, and heart disease, we were able to select a relatively healthy cohort to avoid confounding effects created by devastating illnesses [19, 35, 36]. Confidence in our findings is encouraged because of the consistency in findings on subgroup analyses and by its restriction to non-smokers, stratification by gender, and deletion of those who died within 3 years after the index date.

However, the study also has several limitations. First, the selection of the participants through a private health screening center may have induced bias toward higher socioeconomic class, so our results may not be generalizable 
to individuals with lower incomes. Second, because only the baseline data were used in this study, misclassifications are possible for blood pressure, blood glucose, and BMI during follow-up; however, the single determinations at baseline have enabled us to predict subsequent mortality outcomes. Third, as with other currently available studies of populations dominantly of Chinese ethnicity [8], only a small proportion were obese (3.62\% with BMI $\geq 30 \mathrm{~kg} / \mathrm{m}^{2}$ and $0.39 \% \geq 35 \mathrm{~kg} / \mathrm{m}^{2}$ ). We may have, therefore, underestimated the harmful effects of obesity, especially among the elderly. Fourth, as shown in previous studies, the relationship between obesity and metabolic disorders or other medical complications is complex [37-39], and the observed low obesity-related mortality may be due to medical or public health advances [40]. We were unable to fully tease out any residual effects of obesity on mortality risk that might operate through unrecognized or unmeasured metabolic disorders, although multivariable proportional hazards models were used to control for available possible confounding covariates. Finally, ours is an observational study and, although of longitudinal design, disallows ascertainment of causality.

\section{Conclusions}

In conclusion, the effect of BMI on mortality varies with age. Obesity is associated with a higher mortality risk for younger people aged 20-49 years, while underweight incurs an excess death risk mainly for elders. For those older than 50 years, even a BMI of $18.5-21.9 \mathrm{~kg} / \mathrm{m}^{2}$, usually regarded as a "normal body weight", could increase the mortality rate by $14-25 \%$, compared to a BMI of $22-23.9 \mathrm{~kg} / \mathrm{m}^{2}$. On the other hand, high blood pressure and hyperglycemia generally impose a higher mortality burden than any deviant BMI. From the public health perspective, weightmanagement programs almost certainly need to be tailored according to age. However, life-extension policies warrant attention among all age groups to cardio-metabolic disorders such as hypertension, pre-diabetes, and diabetes.

\section{Additional file}

Additional file 1: Table S1. All-cause mortality risk for subjects overall and those who survived at least 1, 2, and 3 years after entry. Figure $\mathbf{S} 1$. Adjusted mortality risk for different BMl, high blood pressure, hyperglycemia, and waist circumference for overall subjects, non-smokers, men, and women, stratified by age. BMI classification: underweight: $<18.5 \mathrm{~kg} / \mathrm{m}^{2}$, low normal: 18.5-21.9 kg/m², normal: $22-23.9 \mathrm{~kg} / \mathrm{m}^{2}$, overweight: $24-26.9 \mathrm{~kg} / \mathrm{m}^{2}$, obese1: $27-29.9 \mathrm{~kg} / \mathrm{m}^{2}$, obese2: $\geq 30 \mathrm{~kg} / \mathrm{m}^{2}$. The hazards ratios shown in Figure $\mathbf{S 1}$ were derived from Cox proportional hazards models adjusted for gender, age, education level, smoking status, physical activity, and drinking status. Table S2. Mortality rate (per 10,000 person-years) by body mass index, age, and status of metabolic syndrome for the study subjects including previous heart disease and stroke $(N=390,941)$. Table S3. Mortality risk, prevalence, and population attributable burden of mortality for different BMl, high blood pressure, and hyperglycemia in overall subjects and people in different age groups, for the study subjects including previous heart disease and stroke $(N=390,941)$. (DOCX $135 \mathrm{~kb})$

\section{Abbreviations}

BMI: Body mass index; Cl: Confidence interval; CMF: Cardio-metabolic factors; HR: Hazard ratio; LTPA: Leisure time physical activity; MetS: Metabolic syndrome; PAR: Population attributable risk; SD: Standard deviation

\section{Acknowledgements}

Not applicable

\section{Funding}

This study is supported by grants (PH-104-PP-28, PH-105-PP-27) from the National Health Research Institutes, Taiwan, but the data analysis, interpretation and conclusions contained herein do not represent those of the National Health Research Institutes.

\section{Availability of data and materials}

The data that support the findings of this study are available from the MJ Health Management Institution, Taipei, Taiwan, but restrictions apply to the availability of these data, which were used under license for the current study, and so are not publicly available. Data are however available from the authors upon reasonable request and with permission of the MJ Health Management Institution.

\section{Authors' contributions}

$\mathrm{CCH}, \mathrm{CAH}$ designed the study. $\mathrm{CCH}$ drafted the manuscript. YFT performed data analysis. MLW critically reviewed and revised the manuscript. ICW, YHC, ISC, TTL, CKT, CAH helped to interpret the study results and commented on the discussion. Al co-authors approved the final version of the submitted manuscript.

\section{Ethics approval and consent to participate}

The institutional review board at the National Health Research Institutes reviewed and approved this study. The participants in the MJ Health Screening Center have signed an informed consent to release their questionnaire and biomarker data for academic research. All of the data used in this research were authorized by, and received from MJ Health Research Foundation (Authorization Code: MJHRFB2014002C). Any interpretation or conclusion described in this paper does not represent the views of MJ Health Research Foundation.

\section{Consent for publication}

Not applicable

\section{Competing interests}

The authors declare no conflicts of interests.

\section{Publisher's Note}

Springer Nature remains neutral with regard to jurisdictional claims in published maps and institutional affiliations.

\section{Author details}

${ }^{1}$ Institute of Population Health Sciences, National Health Research Institutes, 35 Keyan Road, Zhunan, Miaoli County, Taiwan. ${ }^{2}$ Department of Health Services Administration, China Medical University, Taichung, Taiwan. ${ }^{3}$ Department of Family Medicine, Min-Sheng General Hospital, Taoyuan, Taiwan. ${ }^{4}$ Department of Epidemiology and Preventive Medicine, Monash University, Melbourne, Australia. ${ }^{5}$ Department of Public Health, China Medical University, Taichung, Taiwan. ${ }^{6}$ National Institute of Cancer Research, National Health Research Institutes, Zhunan, Taiwan. ${ }^{7} \mathrm{MJ}$ Health Management Institution, Taipei, Taiwan.

Received: 23 January 2017 Accepted: 5 January 2018

Published online: 14 February 2018

\section{References}

1. Whitlock G, Lewington S, Sherliker P, Clarke R, Emberson J, Halsey J, et al. Body-mass index and cause-specific mortality in 900000 adults: collaborative analyses of 57 prospective studies. Lancet. 2009;373:1083-96.

2. Wang Y, Rimm EB, Stampfer MJ, Willett WC, Comparison HFB. Of abdominal adiposity and overall obesity in predicting risk of type 2 diabetes among men. Am J Clin Nutr. 2005:81:555-63.

3. Truswell AS. Medical history of obesity. Nutrition and Medicine. 2013;1(1)(2):2. 
4. Jee SH, Sull JW, Park J, Lee SY, Ohrr H, Guallar E, et al. Body-mass index and mortality in Korean men and women. N Engl J Med. 2006;355:779-87.

5. Berrington de Gonzalez A, Hartge P, Cerhan JR, Flint AJ, Hannan L, Maclnnis $\mathrm{RJ}$, et al. Body-mass index and mortality among 1.46 million white adults. N Engl J Med. 2010;363:2211-9.

6. Pischon $T$, Boeing $H$, Hoffmann $K$, Bergmann M, Schulze MB, Overvad $K$, et al. General and abdominal adiposity and risk of death in Europe. N Engl J Med. 2008;359:2105-20.

7. Lin WY, Tsai SL, Albu JB, Lin CC, Li TC, Pi-Sunyer FX, et al. Body mass index and all-cause mortality in a large Chinese cohort. CMAJ. 2011;183:E329-36.

8. Gu D, He J, Duan X, Reynolds K, Wu X, Chen J, et al. Body weight and mortality among men and women in China. JAMA. 2006;295:776-83.

9. Heymsfield SB, Cefalu WT. Does body mass index adequately convey a patient's mortality risk? JAMA. 2013;309:87-8.

10. Locher $\mathrm{J}$, Roth $\mathrm{DL}$, Ritchie CS, Cox K, Sawyer P, Bodner EV, et al. Body mass index, weight loss, and mortality in community-dwelling older adults. J Gerontol A Biol Sci Med Sci. 2007:62:1389-92.

11. Tamakoshi A, Yatsuya H, Lin Y, Tamakoshi K, Kondo T, Suzuki S, et al. BMI and all-cause mortality among Japanese older adults: findings from the Japan collaborative cohort study. Obesity (Silver Spring). 2010;18:362-9.

12. Stevens J, Cai J, Pamuk ER, Williamson DF, Thun MJ, Wood JL. The effect of age on the association between body-mass index and mortality. N Engl J Med. 1998;338:1-7.

13. Grabowski DC, Ellis JE. High body mass index does not predict mortality in older people: analysis of the longitudinal study of aging. J Am Geriatr Soc. 2001;49:968-79.

14. Thinggaard M, Jacobsen R, Jeune B, Martinussen T, Christensen Kl. The relationship between $\mathrm{BMI}$ and mortality increasingly $U$-shaped with advancing age? A 10-year follow-up of persons aged 70-95 years. J Gerontol A Biol Sci Med Sci. 2010;65:526-31.

15. Cohen-Mansfield J, Perach RI. There a reversal in the effect of obesity on mortality in old age? J Aging Res. 2011;2011:765071.

16. Kuk $\mathrm{L}$, Ardern $\mathrm{Cl}$. Influence of age on the association between various measures of obesity and all-cause mortality. J Am Geriatr Soc. 2009;57:2077-84.

17. Arnlov J, Ingelsson E, Sundstrom J, Lind L. Impact of body mass index and the metabolic syndrome on the risk of cardiovascular disease and death in middle-aged men. Circulation. 2010;121:230-6.

18. Wormser D, Kaptoge S, Di Angelantonio E, Wood AM, Pennells L, Thompson $A$, et al. Separate and combined associations of body-mass index and abdominal adiposity with cardiovascular disease: collaborative analysis of 58 prospective studies. Lancet. 2011;377:1085-95.

19. Wahlqvist ML, Chang HY, Chen CC, Hsu CC, Chang WC, Wang WS, et al. Is impaired energy regulation the core of the metabolic syndrome in various ethnic groups of the USA and Taiwan? BMC Endocr Disord. 2010;10:11

20. Flegal KM, Kit BK, Orpana H, Graubard BI. Association of all-cause mortality with overweight and obesity using standard body mass index categories: a systematic review and meta-analysis. JAMA. 2013;309:71-82.

21. Ford ES, Giles WH, Dietz WH. Prevalence of the metabolic syndrome among US adults: findings from the third National Health and nutrition examination survey. JAMA. 2002;287:356-9.

22. Wen CP, Cheng TY, Tsai MK, Chang YC, Chan HT, Tsai SP, et al. All-cause mortality attributable to chronic kidney disease: a prospective cohort study based on 462293 adults in Taiwan. Lancet. 2008;371:2173-82.

23. Pan WH, Lee MS, Chuang SY, Lin YC, Obesity FML. Pandemic, correlated factors and guidelines to define, screen and manage obesity in Taiwan. Obes Rev. 2008;9(Suppl 1):22-31.

24. WHO. Obesity: preventing and managing the global epidemic. Report of a WHO consultation. World Health Organ Tech Rep Ser. 2000;894:1-253.

25. Wang WS, Wahlqvist ML, Hsu CC, Chang HY, Chang WC, Chen CC. Age- and gender-specific population attributable risks of metabolic disorders on allcause and cardiovascular mortality in Taiwan. BMC Public Health. 2012:12:111.

26. Rothman KJ. BMI-related errors in the measurement of obesity. Int J Obes. 2008:32(Suppl 3):S56-9.

27. Wahlqvist ML, Chuang SY. Paradoxes with weight disorders for health systems. Asia Pac J Clin Nutr. 2012;21:471-5.

28. Manson JE, Willett WC, Stampfer MJ, Colditz GA, Hunter DJ, Hankinson SE, et al. Body weight and mortality among women. N Engl J Med. 1995;333: 677-85.

29. Lee IM, Manson JE, Hennekens CH, Paffenbarger RS Jr. Body weight and mortality. A 27-year follow-up of middle-aged men. JAMA. 1993;270:2823-8.
30. Galassi A, Reynolds K, He J. Metabolic syndrome and risk of cardiovascular disease: a meta-analysis. Am J Med. 2006:119:812-9.

31. Hildrum B, Mykletun A, Dahl AA, Midthjell K. Metabolic syndrome and risk of mortality in middle-aged versus elderly individuals: the Nord-Trondelag health study (HUNT). Diabetologia. 2009;52:583-90.

32. Thomas F, Pannier B, Benetos A, Vischer UM. The impact of the metabolic syndrome-but not of hypertension-on all-cause mortality disappears in the elderly. J Hypertens. 2011;29:663-8.

33. Lee MS, Huang YC, Wahlqvist ML. Chewing ability in conjunction with food intake and energy status in later life affects survival in Taiwanese with the metabolic syndrome. J Am Geriatr Soc. 2010:58:1072-80.

34. Mozaffarian D, Kamineni A, Prineas RJ, Siscovick DS. Metabolic syndrome and mortality in older adults: the cardiovascular health study. Arch Intern Med. 2008;168:969-78.

35. Manson JE, Stampfer MJ, Hennekens CH, Willett WC. Body weight and longevity. A reassessment. JAMA. 1987;257:353-8.

36. Simopoulos AP, Van Itallie TB. Body weight, health, and longevity. Ann Intern Med. 1984;100:285-95.

37. Landsberg L, Aronne LJ, Beilin LJ, Burke V, Igel LI, Lloyd-Jones D, et al. Obesity-related hypertension: pathogenesis, cardiovascular risk, and treatment: a position paper of the Obesity Society and the American Society of Hypertension. J Clin Hypertens (Greenwich). 2013;15:14-33.

38. Mokdad AH, Ford ES, Bowman BA, Dietz WH, Vinicor F, Bales VS, et al. Prevalence of obesity, diabetes, and obesity-related health risk factors, 2001. JAMA. 2003;289:76-9.

39. Villareal DT, Apovian CM, Kushner RF, Klein S. Obesity in older adults: technical review and position statement of the American Society for Nutrition and NAASO, the Obesity Society. Am J Clin Nutr. 2005;82:923-34.

40. Pan WH, Yeh WT, Chen HJ, Chuang SY, Chang HY, Chen L, et al. The Ushaped relationship between BMI and all-cause mortality contrasts with a progressive increase in medical expenditure: a prospective cohort study. Asia Pac J Clin Nutr. 2012;21:577-87.

\section{Submit your next manuscript to BioMed Central and we will help you at every step:}

- We accept pre-submission inquiries

- Our selector tool helps you to find the most relevant journal

- We provide round the clock customer support

- Convenient online submission

- Thorough peer review

- Inclusion in PubMed and all major indexing services

- Maximum visibility for your research

Submit your manuscript at www.biomedcentral.com/submit 